\title{
Hombre, persona y dignidad
}

\author{
Man, Person and Dignity \\ Carlos Ramos Rosete \\ Universidad Popular Autónoma del Estado de Puebla \\ carlos.ramos@upaep.mx
}

\section{RESUMEN}

Toda disciplina de tipo humanista o de carácter social asume como uno de sus presupuestos fundamentales una noción de lo que es el ser humano. Llevar a cabo una reflexión de tipo filosófico sobre las nociones de hombre, persona y dignidad se vuelve imprescindible para aclarar elementos antropológicos que son fundamentos teóricos de las ciencias humanas y sociales. La palabra "hombre" admite significados que en parte coinciden y en parte difieren con la noción de persona. La expresión "persona humana" no es siempre una redundancia. Siguiendo el pensamiento de Santo Tomás de Aquino, que distingue entre las nociones de hombre y persona, la subsistencia de la persona humana se vuelve fundamento de la dignidad humana y fuente de los derechos humanos.

Palabras clave: hombre, persona humana, subsistencia, dignidad, personalismo

\section{Abstract}

All humanist or social discipline assumes as one of its fundamental principles an idea of what human being is. Accomplishing a philosophical reflection about the man notions, person and dignity become essential to clarify antropological elements which are theorical fundaments of human and social sciences. The Word man accepts meanings that are partly the same and partly different with the concept of human person, in some way, is not totally a redundancy. Following Saint Thomas Aquinas's thought who distinguishes between the notions of man and person, it is noted that the subsistency of the human person turns into the human dignity basis and source of all human rights.

Keywords: man, human person, subsistence, dignity, personalism 


\section{Precisiones semánticas}

El término o la palabra Hombre puede tener las siguientes significaciones:

Hombre como varón: Algunas veces se utiliza para designar al sujeto humano de sexo masculino, varón, que es distinto del sujeto humano de sexo femenino, mujer o dama; y así se dice: Juan es hombre y Leticia no es hombre sino mujer.

Hombre como Humanidad: En otras ocasiones es usada para referirse a la humanidad como un colectivo que agrupa al conjunto de personas (tanto varones como mujeres) que han existido en el pasado, existen en el presente y existirán en el futuro. Y así se dice: el avance científico del hombre o el avance científico de la humanidad, o bien, la historia del hombre o la historia de la humanidad.

Hombre como la esencia de algunos individuos: Cuando se pregunta ¿qué es el hombre?, se está buscando una respuesta que incluya una serie de elementos que identifiquen a un determinado tipo de seres que no son cuerpos físicos inertes (como las rocas o minerales) o que no son vegetales; o bien, que no son animales; es decir, a unos seres biológicos cuyo modo de ser los hace distintos de los objetos, de los vegetales y de los animales. He aquí la siguiente pregunta: ¿cuáles son aquellos elementos esenciales que identifican como seres humanos tanto a los varones como a las mujeres? Con relación a la respuesta de esta última pregunta, el filósofo Max Scheler comenta:

Si se pregunta a un europeo culto lo que piensa al oír la palabra hombre, casi siempre empezarán a rivalizar en su cabeza tres círculos de ideas... Primero, el círculo de ideas de la tradición judeo-cristiana: Adán y Eva, la Creación, el Paraíso, la caída. Segundo, el círculo de ideas de la antigüedad clásica; aquí la conciencia que el hombre tiene de sí mismo se elevó [...] a un concepto de su posición singular mediante la tesis de que el hombre es hombre porque posee "razón", logos, fronesis, ratio, mens, etc., donde logos significa tanto la palabra como la facultad de apresar el "qué" de todas las cosas [...]. El tercer círculo de ideas es el círculo de las ideas forjadas por la ciencia moderna de la naturaleza y por la psicología genética [...], según estas ideas, el hombre sería un producto final y muy tardío de la evolución del planeta Tierra, un ser que sólo se distinguiría de sus precursores en el reino animal por el grado de complicación con que se combinaría en él energía y facultades que en sí ya existen en la naturaleza infrahumana [...]. Poseemos, pues una antropología científica, otra filosófica y otra teológica $[\ldots] .{ }^{1}$

\footnotetext{
1 Scheler, Max, El puesto del hombre en el cosmos, Buenos Aires: Losada, 1997, pp. 23-24.
} 
¿Qué es el hombre? Según la tradición judeo-cristiana, es imagen y semejanza de Dios; según la tradición griega vía Aristóteles es un animal racional o un animal político; y según la teoría de la evolución vía Carlos Darwin es un primate cuya evolución biológica ha derivado gradualmente, pero no específicamente, en una evolución cultural pensante, y tal primate queda clasificado como homo sapiens.

La palabra hombre también se usa para designar al sujeto particular que es un ser humano, o sea, para referirse al sujeto humano singular en su profunda y total realidad que es un varón o una mujer, y de esta manera se dice: "este" ser humano que es Juan es distinto a "este" otro ser humano que es Leticia. En este sentido, el filósofo español Miguel de Unamuno y Jugo escribe:

Homo sum; nihil humani a me alienum puto, dijo el cómico latino. Yo diría más bien: nullum hominem a me alienum puto; soy hombre, a ningún otro hombre estimo extraño. Porque el adjetivo humanus me es tan sospechoso como su sustantivo abstracto humanitas, la humanidad. Ni lo humano ni la humanidad, ni el adjetivo simple, ni el adjetivo sustantivado, sino el sustantivo concreto: el hombre. El hombre de carne y hueso, el que nace, sufre y muere -sobre todo muere-, el que come y bebe y juega y duerme y piensa y quiere; el hombre que se ve y a quien se oye, el hermano, el verdadero hermano. Porque hay otra cosa, que llaman también hombre, y es el sujeto de no pocas divagaciones más o menos científicas. Y es el bípedo implume de la leyenda, el Zoon Politikón de Aristóteles, el contratante social de Rousseau, el homo economicus de los manchesterianos, el homo sapiens, de Lineo, o, si se quiere, el mamífero vertical. Un hombre que no es de aquí o de allí, ni de esta época o de la otra; que no tiene sexo ni patria, una idea, en fin. Es decir, un no hombre. El nuestro es el otro, el de carne y hueso; yo, tú, lector mío; aquel otro de más allá, cuantos pisamos sobre la tierra. Y este hombre concreto, de carne y hueso, es el sujeto y el supremo objeto a la vez de toda filosofía, quiéranlo o no ciertos sedicentes filósofos. ${ }^{2}$

Bajo esta acepción, la palabra Hombre se vuelve sinónimo de persona humana para indicar a un sujeto humano en particular.

2 Unamuno, Miguel de, Del sentimiento trágico de la vida, México: Porrúa (Sepan cuántos, 402), 2003, p. 3. 


\section{Evolución etimológica del término persona}

Por su parte, el término persona proviene de la voz latina personare, que significa "sonar con fuerza" o bien "resonar", haciendo alusión a las máscaras que usaban los actores griegos para que su voz adquiriera mayor resonancia; así entonces, se dice persona según su origen greco-latino porque intensifica el sonido y designa originalmente la careta-megáfono de uso teatral. Por otra parte, los griegos designaban con la voz "prosopón" a la máscara que va delante de la cara o rostro, dando a entender que la máscara busca ocultar el propio rostro y hace aparecer "otro" rostro distinto a los ojos de quien los ve, de tal modo que el actor asume el papel del sujeto personificado por la máscara.

Boecio señala, por tanto, dos etimologías del término persona. Según la primera, el nombre de persona proviene del término griego -prosopón- que significa cara o semblante. Con este término se nombraba a los personajes del teatro, pues para interpretarlos los actores utilizaban caras artificiales. También persona, según Boecio, derivaría del término latino -persono-, que significa sonar con fuerza o resonar, que aludiría con ello al sonido que adquiría la voz de los actores con sus máscaras. ${ }^{3}$

Siguiendo la anterior tradición, el término persono o personare, y su equivalente prosopón, evocaban más bien la máscara de teatro y no tanto al hombre singular.

Santo Tomás introduce el término Hipóstasis, relacionándolo con el término persona, y en otro pasaje, el mismo Santo Tomás nos refiere la significación griega del término Hipóstasis: "Para los griegos, Hipóstasis significa etimológicamente, individuo en el género substancia". ${ }^{4}$

De ahí que el término Hipóstasis hace referencia a la substancia individual sujeto de los accidentes. ¿Por qué Santo Tomás hace una relación entre los términos Persona e Hipóstasis? Porque cuando se buscaba expresar en términos adecuados (para no caer en herejía) lo que era el Misterio Trinitario, los Padres de la Iglesia tenían, por una parte, los términos prosopón y personare (griego y latino, respectivamente); y por otra, el término Hipóstasis (también de origen griego). Con los dos primeros, Prosopón y Personare, se hacía referencia a la máscara-megáfono; y con el segundo, Hipóstasis, se hacía referencia a la substancia individual o particular. Lo anterior no dejó de ocasionar una serie de controversias para expresar el Misterio de la Santísima Trinidad,

3 Forment, Giralt Eudaldo, Ser y persona, Barcelona: Ediciones de la Universidad de Barcelona, 1982, p. 51.

4 Sth. 1, 29, 3, ad. 1. 
y así, por ejemplo, los Padres griegos prefirieron expresarlo de la siguiente forma: "Una sola Naturaleza y tres Hipóstasis", ya que el nombre de Persona evocaba más bien la máscara de teatro implicando el carácter aparente y representativo de un sujeto, más no su carácter real.

Santo Tomás, por su parte, menciona que el concepto de Hipóstasis se puede aplicar a todo sujeto de los accidentes o substancia primera, en cambio, el término persona designa no cualquier substancia primera (Hipóstasis) sino aquella que es de naturaleza racional: "Así este hombre es una realidad natural humana. Por ser supuesto de los accidentes es llamado Hipóstasis o subsistencia [...]. El nombre de persona sólo lo es en el género de las substancias racionales" ${ }^{5}$

En resumen, de la palabra persona entendida como careta-megáfono, se pasó a entenderla, con los romanos, como referida a alguien que sobresale en su rol social, ligándose al término dignidad, para finalmente entenderla como un sujeto individual que subsiste en la naturaleza racional en la teología de Santo Tomás de Aquino.

\section{El ser humano como persona}

Resulta hoy urgente, quizás más que nunca, interrogarse acerca de qué es el ser humano en tanto sujeto, es decir, en tanto persona. Empujado por las biotecnologías, el hombre vuelve a plantearse la eterna pregunta sobre sí mismo y su destino. Esto es perfectamente comprensible. Las soluciones a los nuevos problemas desatados por los desarrollos biomédicos dependen casi enteramente de la respuesta que se dé a la pregunta sobre la persona. ${ }^{6}$

No es lo mismo que un varón y/o mujer se pregunte "¿qué soy?" a que se pregunte "¿quién soy?"; lo primero apunta a una definición esencial, y en este sentido se podría responder: "soy un animal racional", "soy imagen y semejanza de Dios"; o bien esa primera pregunta puede apuntar a una característica derivada de la esencia humana a como lo es la determinación sexual, y en este sentido, se podría responder: "soy varón" o "soy mujer". En cambio, la segunda pregunta, "¿quién soy?", apunta a una singularidad de lo humano que se concreta en un carácter personal de modo particular.

Sth. 1, 29, 2.

6 Andorno, Roberto, Bioética y dignidad de la persona, Madrid: Tecnos, 2012, p. 67. 
Entender al ser humano como animal racional u Homo Sapiens es ubicarse a un nivel esencial o categorial; empero, entenderlo como persona es ubicarse a un nivel de subsistencia particular, y así por ejemplo, Pedro y Pablo tienen gran semejanza a nivel esencial en cuanto que son ejemplares de animales racionales o de Homo Sapiens, sin embargo, como personas que subsisten de modo singular, son muy diferentes.

Santo Tomás de Aquino, comentando la definición de persona que estableció el pensador Boecio dice: "La definición de persona que Boecio asigna en el libro De las dos naturalezas es la siguiente: la persona es la substancia individual de naturaleza racional" ${ }^{7}$

La definición de persona de Boecio es mucho más rica que la definición aristotélica de hombre como animal racional, pues, siguiendo la definición de Boecio, la persona humana no designa principalmente a una esencia humana expresada en el concepto universal de "animal racional", sino más bien se refiere a este hombre singular, pues la definición de persona de Boecio está designando a un modo de ser substancial individual con toda su concreción, que se realiza singularmente como naturaleza racional, con lo cual, si se define a la persona como substancia individual de naturaleza racional, no se está definiendo una esencia abstracta universal, sino un modo de subsistir concreto: "Así, el nombre de individual entra en la definición de persona para indicar el modo de subsistir propio de las substancias particulares" ${ }^{8}$

Contrariamente, la definición aristotélica de hombre está referida no a un modo de ser substancial individual, sino a la esencia universal de ser humano, que es lo animal y lo racional común a varios sujetos.

Entender al ser humano como persona humana implica dos cosas:

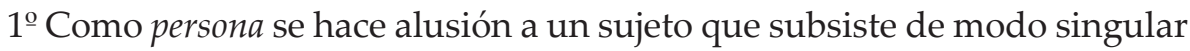
único e irrepetible.

$2^{\underline{0}}$ Como humano se hace alusión a un modo esencial que varios sujetos pueden realizar de modo semejante.

Sth. $1,29,1$.

8 Sth. 1, 29, 1, ad. 3. 


\section{La persona humana como un sujeto subsistente singular}

La subsistencia y la singularidad son elementos correlativos al ser personal, siendo evidente que una persona no es la otra, y así por ejemplo, la persona humana que es Pedro es distinta de la persona humana que es Leticia, a pesar de que ambas son personas humanas. Lo anterior se debe a que cada persona subsiste de modo singular, siendo cada persona única e irrepetible: "Lo que hace que Sócrates sea hombre pueden tenerlo muchos, pero lo que hace que Sócrates sea este hombre sólo puede tenerlo uno". ${ }^{9}$

Si cada persona humana es singular y por ende irremplazable, entonces cada persona es distinta de otra, pero dicha distinción queda fundada en la subsistencia personal, por ello Santo Tomás menciona en una parte de la suma teológica: "Por lo tanto, en cualquier naturaleza, persona significa lo que es distinto en aquella naturaleza". ${ }^{10}$

El que una persona sea distinta de las demás, ontológicamente, significa la negación de que una determinada persona sea la otra en razón de que cada persona es un sujeto subsistente singular, y así, aunque una característica humana pueda ser común a dos o más personas, dicha característica se realiza de un modo exclusivo y único en cada persona, pues en cuanto que tal o cual característica se integra a la subsistencia personal singular, dicha característica se singulariza en "esta" persona en concreto; de este modo, se puede decir que no es el entendimiento el que entiende, sino que cada persona humana lo hace por medio de su propio entendimiento, e igualmente, aunque Pedro y Leticia sean muy semejantes en vivir la virtud de la justicia, dicha virtud se realiza de modo único e irrepetible en cada una de ellos, porque la persona humana que es Pedro como sujeto subsistente es realmente distinta de la persona humana que es Leticia. Todo lo anterior tiene sus consecuencias en el dinamismo personal, y así por ejemplo, no hay nadie que pueda querer en lugar mío, puesto que yo soy yo, y nadie puede ser yo para querer en lugar mío, de ahí que cada quien sea responsable de sus actos libres.

A nivel biológico, la singularidad personal se expresa en un genoma particular, presente ya en el cigoto humano, pero en este punto es muy importante hacer la siguiente precisión: una persona humana es singular no porque tenga un genoma individual, sino que ese genoma individual es propio de una persona humana en particular porque tal persona subsiste de modo singular, de ahí que se mencione que la individualidad genética sea

Sth. 1, 11, 3 .

${ }^{10}$ Sth. 1, 29, 4 . 
una expresión a nivel biológico de la subsistencia y singularidad ontológica de cada persona humana.

Por otra parte, la subsistencia no sólo implica singularidad en la persona, sino que también implica el hecho de que cada ser humano es un todo personal. Cada persona es un todo completo, y por consiguiente, cada ser humano para ser una persona humana no necesita ser parte de otro o inherir en otro sujeto para ser tal; es decir, la subsistencia personal no es algo que sea predicable a otro sujeto a como lo es la esencia que se puede predicar de muchos sujetos: Leticia es un animal racional, Pedro es un animal racional, Juan es un animal racional, etc. Cuando se entiende a la persona humana como un sujeto subsistente singular, su carácter de totalidad niega el que se pueda predicar de muchos sujetos del mismo modo a como se hace con la definición aristotélica de hombre como animal racional; lo anterior se debe a que cada persona, como un sujeto subsistente singular que es, realiza su subsistencia como un todo íntegro y completo de: cuerpo y alma humana, actos intelectivos, actos volitivos, actos biológicos, determinaciones accidentales, elementos químicos, partículas atómicas y subatómicas, etc.; y la unión de todo lo anterior no se constituye como un simple agregado sin más que es la persona humana, sino que todas las partes antes mencionadas se dan integradas en cada persona humana en una unidad rica, compleja y variada, realizadas subsistentemente en Pedro, Juan, Leticia, etc.

El considerar a la persona humana como un todo subsistente singular es muy importante para no reducir a la persona humana a una de sus manifestaciones, ya sea a nivel biológico, psicológico o social, pues dichas cualidades, aunque manifiesten la personalidad de alguien y evidencien un carácter personal, tienen realidad precisamente en la misma subsistencia personal, pues fuera de ésta nada son.

La persona humana es un todo subsistente singular, en donde lo humano denota algo propio de los varones y las mujeres que los distingue, en la mentalidad cristiana, de las personas angélicas y las Personas Divinas. Lo humano de la persona hace que ésta asuma dentro de su subsistencia a un cuerpo biológico ligado a una evolución de las especies desde el punto de vista filogenético, y a un desarrollo individual que va desde el cigoto hasta la ancianidad desde un punto de vista ontogenético.

La persona humana, por ser persona, es un sujeto subsistente singular de naturaleza racional, pero como en tal subsistencia está integrado un cuerpo biológico compuesto por sistemas y aparatos, entonces la subsistencia del varón y la mujer queda humanizada. Ahora bien, es muy importante aclarar que la persona humana no es tal por incluir un cuerpo biológico, pues el cuerpo biológico se ordena a la subsistencia de la persona y no la subsistencia al 
cuerpo biológico, es decir, el cuerpo biológico humano sólo es una totalidad orgánica que jerarquiza sus diversos aparatos y sistemas en una distribución antropomórfica cuanto está integrado a la subsistencia personal de naturaleza racional; fuera de esta subsistencia, el cuerpo biológico, aunque conserva aquellos elementos distintivos de la biología humana, como un genoma determinado, ya no es una totalidad orgánica. En este sentido, la muerte en la persona humana afecta intrínsecamente a su subsistencia, pues por la muerte la persona humana pierde su cuerpo hasta el punto de dejar de ser persona. Pero hay que insistir en que la persona humana no es humana por su cuerpo biológico, sino que la subsistencia personal se humaniza al ordenar para sí al cuerpo biológico, de tal modo, que el cuerpo biológico de un varón o de una mujer es humano en razón de estar integrado en una subsistencia de naturaleza racional que exige realizarse biológicamente, pues el cuerpo biológico se ordena a la subsistencia. El cuerpo bilógico es principio de humanización en la persona, pero lo que causa que ese cuerpo biológico se humanice es su ordenación a la subsistencia de la naturaleza racional. En este sentido, el cadáver de una persona humana ya no es persona, sino materia orgánica en descomposición cuya bioquímica sigue manteniendo una afinidad hacia lo humano; por eso, la expresión "restos humanos" no deja de ser muy significativa; "restos": aquello que fue persona humana; "humanos": esa materia orgánica sigue siendo compatible a nivel corpóreo con lo humano, pero ya en un proceso de descomposición.

Aunque el cuerpo biológico es principio de humanización en la persona, la humanización se da de hecho en la medida en que el cuerpo biológico está integrado en la subsistencia de la persona. De ahí que el cuerpo biológico esté no sólo humanizado en el subsistir de la persona, sino que también esté personalizado, y en este sentido, no es el cuerpo el que, por ejemplo, hace la digestión, sino que es la persona que hace la digestión en su cuerpo.

\section{La dignidad personal}

He comentado que en la tradición grecolatina más pura la palabra persona y su equivalente prosopón designaban la resonancia de la máscara cuya concavidad reforzaba la voz y la hacía resaltar; y por ello se relacionó la palabra persona con la noción de lo sobresaliente o importante que resalta, de tal modo que para los romanos la palabra latina personare pasó a significar ya no tanto la máscara, sino más bien la vida o rol social que cada sujeto desempeñaba en la sociedad según su importancia en la escala social. Santo Tomás de Aquino menciona algo semejante respecto a este último punto -repito la cita anotada líneas arriba-: “En las comedias y en las tragedias se representaba 
a personajes famosos, se impuso pues el nombre de persona para indicar a alguien con dignidad. Por eso en las iglesias empezó la costumbre de llamar persona a los que tienen alguna dignidad". ${ }^{11}$

En este pasaje de la Suma Teológica, el término persona se empieza a ligar con el término dignidad como algo sobresaliente. La palabra "dignidad" hace alusión, fundamental y primariamente, a la "preeminencia", a la "excelencia" (de excellere: destacar). Digno es aquello por lo que algo destaca entre otros entes, en razón de un valor que le es propio. Con lo cual, la expresión "dignidad de la persona" que actualmente se usa, destaca en la persona un carácter que le es resaltante y exclusivo sólo de ella. Algunas corrientes antropológicas centradas en la persona han interpretado el concepto como la valoración de la persona humana como fin que vale en sí misma, ya que "digno" es aquello que debe ser tratado con "respeto", es decir, "con miramiento" (respetus), con veneración. De ahí que, en rigor, hablar de la dignidad de la persona resulte un pleonasmo, o se trate quizá de una redundancia intencionada para resaltar o subrayar la altura del rango que ocupa ese tipo de entes en el orden del universo que son las personas.

- A la luz de la profundización metafísica que hace Santo Tomás de Aquino cuando menciona: "Persona significa lo que en toda naturaleza es perfectísimo, es decir, aquello que subsiste en la naturaleza racional" ${ }^{12}$ Y también: "Como quiera que subsistir en la naturaleza racional es de la máxima dignidad, todo individuo de naturaleza racional es llamado persona". ${ }^{13}$

- El planteamiento de la persona como un sujeto subsistente de naturaleza racional, se vuelve vital para la fundamentación metafísica de la dignidad personal y los derechos humanos que se siguen de dicha dignidad con la siguiente doble consecuencia:

a) El ser humano como persona, en sentido estricto, no tiene dignidad, sino que es dignidad. El valor de ser persona es más noble que cualquier otro valor, sea éste moral, económico, social, etc.

Este rol central de la dignidad está en consonancia con la idea comúnmente admitida de que ella representa un valor absoluto o incondicional, mientras que los demás valores humanos, incluso los más importantes, son en alguna medida relativos y admiten excepciones. Esto significa que

\footnotetext{
${ }^{11}$ Sth. 1, 29, 3, ad. 2.

${ }^{12}$ Sth. 1, 29, 3.

${ }^{13}$ Sth. 1, 29, 3. Ad. 2.
} 
nunca y bajo ninguna circunstancia podemos someter a una persona a un tratamiento indigno. ${ }^{14}$

b) Los derechos humanos que se siguen de la persona dan sentido a toda ley jurídica y a toda sociedad humana. Empero, si se hace caso omiso de ese planteamiento metafísico (como tiende a bien hacer el iuspositivismo), entonces se tiene como consecuencia que el fundamento de los derechos humanos, que son la persona y su dignidad, se plantearán a-posteriori de la ley jurídica y de la sociedad, con lo cual se abre paso a la idea de que los derechos humanos se consensan en el Parlamento o Congreso según la voluntad de la mayoría.

La dignidad de la persona es algo analógico, es decir, hay tipos de dignidad en la persona humana según un orden. Existe una dignidad ontológica en la persona humana en razón de su subsistencia en la naturaleza racional. Existe también una dignidad moral que se sigue del actuar libre de la persona. Existe una dignidad social que se sigue de la posición o rol social que una persona ocupa hacia dentro de una comunidad, e incluso, si se toma en cuenta la tradición judeocristiana, se tiene una dignidad religiosa que se sigue de la condición creatural de la persona humana como imagen y semejanza de Dios.

La dignidad ontológica es aquella que todo hombre tiene como persona que $e s_{\iota}$ es decir, que subsiste en la naturaleza racional de modo singular. Esta dignidad ontológica es difícil de explicar por ser un dato de primer orden a nivel del ser personal:

Tiene razón Reinhard Löw cuando rechaza la posibilidad de definir con exactitud y de manera exhaustiva la noción de dignidad. Estamos ante una de esas realidades tan primarias, tan principales, que resultan poco menos que evidentes y que, por tanto, no cabe esclarecer mediante conceptos más notorios. ${ }^{15}$

El que la dignidad ontológica sea en última instancia inefable significa que es irreductible a un concepto porque la persona humana no es una idea, sino una realidad subsistente que exige reconocimiento y respeto antes que una definición. Por otra parte, se pueden describir cuatro elementos distintivos de la dignidad ontológica: su carácter congénito, su carácter intrínseco, su carácter inalienable y su carácter singular.

La dignidad ontológica es congénita porque está presente en el mismo origen de cada persona humana, es decir, tal dignidad es poseída por la persona desde que ésta es originada en su existencia intrauterina, y por consiguiente,

\footnotetext{
${ }^{14}$ Andorno, Roberto, Bioética y dignidad de la persona, p. 36.

${ }^{15}$ Melendo, Tomás, Las dimensiones de la persona, Madrid: Palabra, 1999, pp. 22-23.
} 
cuando la persona nace, ya previamente posee su dignidad ontológica. De ahí que sobrevenga inmediatamente la pregunta: ¿desde cuándo la persona es originada en su existencia intrauterina? La respuesta a esta pregunta es uno de los cuestionamientos de la bioética, cuando esta disciplina aborda el tema del estatuto ontológico del embrión humano.

La dignidad ontológica es intrínseca no en un sentido biológico, sino más bien en un sentido precisamente ontológico. La dignidad ontológica no es intrínseca, como lo son los diversos órganos del cuerpo humano, sino que su carácter intrínseco significa que abarca a toda la persona como un todo y a cada una de sus partes en cuanto están integradas al todo personal; de esto último se siguen tres consecuencias:

a. Cada parte corpórea de la persona humana, en cuanto que se encuentra integrada al todo subsistente personal, participa plenamente de la dignidad ontológica de una persona en singular. En este sentido, lesionar injustamente una parte del cuerpo humano vivo es siempre un atentado en contra de esa dignidad ontológica.

b. Aunque una persona pierda alguna parte de su cuerpo, por ejemplo, la amputación de sus cuatro extremidades, su dignidad ontológica no disminuye en lo más mínimo.

c. La dignidad ontológica es igual en todas las personas, pero merece más respeto en condiciones biológicas iniciales, limitadas y de debilidad.

El racismo comete el error de fundamentar la dignidad ontológica en una característica corporal, de ahí la falsa consecuencia de mencionar que las personas de color oscuro no sean propiamente personas con relación a las personas blancas que sí poseen dignidad ontológica en razón del color claro de su piel.

La dignidad ontológica es inalienable en cuanto que no es transferible o pueda ser desprendida de la persona, como se puede desprender de ésta una parte de su cuerpo. El carácter inalienable significa que tal dignidad está presente en la persona desde su origen hasta su muerte. Otra palabra para significar esta característica de la dignidad ontológica es el término irrenunciable, es decir, el ser humano en cuanto persona, siempre y en todo momento, posee su dignidad ontológica, y le es imposible separarse de ella.

La dignidad ontológica es singular porque es propia en cada persona concreta que subsiste en la naturaleza racional, es decir, toda persona humana en cuanto que es "esta" persona en singular, tiene un valor único, irrepetible e irremplazable. Afirma Zurriaráin: 
Cuando hablamos de "dignidad humana" no nos estamos refiriendo a la humanidad en general, sino a los hombres concretos; son ellos, y no la humanidad en general, los que son dignos, los que con su sola presencia demandan de los demás un trato respetuoso. Más todavía, el respeto por la dignidad de cada ser humano radica en el respeto por la dignidad de su cuerpo que se constituye en el primer día de su existencia. ${ }^{16}$

Y agrega: "Dignos son cada uno de los seres humanos concretos que realiza la especie a la que pertenece de un modo original, único e irrepetible. Cada hombre es digno por ser lo que es, por existir como individuo humano". ${ }^{17}$

La dignidad ontológica del ser humano es manifestativa de su carácter personal enraizada en la misma subsistencia personal.

La dignidad humana corresponde, desde el plano ontológico, a cada uno de los seres humanos. El hombre es digno por lo que es. No se es más o menos humano, más o menos digno, dependiendo del cumplimiento de una serie de requisitos o características... Esta dignidad [ontológica] es la misma para todos en cuanto se descubre en el hombre por el sólo hecho de existir, por el hecho exclusivo de ser hombre. La dignidad ontológica, por tanto, tiene un carácter fundante y acompaña necesariamente a todo ser humano por el sólo hecho de serlo. ${ }^{18}$

La dignidad ontológica es el fundamento de los derechos humanos como su fuente primaria. En este sentido, la Declaración Universal de los Derechos Humanos de 1948 afirma en sus párrafos iniciales:

Considerando que la libertad, la justicia y la paz en el mundo tienen por base el reconocimiento de la dignidad intrínseca y de los derechos iguales e inalienables de todos los miembros de la familia humana... (Preámbulo)

Considerando que el desconocimiento y el menosprecio de los derechos humanos han originado actos de barbarie ultrajantes para la conciencia de la humanidad... (Preámbulo)

Considerando esencial que los derechos humanos sean protegidos por un régimen de Derecho... (Preámbulo)

Todos los seres humanos nacen libres e iguales en dignidad y derechos y, dotados como están de razón y conciencia, deben comportarse fraternalmente los unos con los otros (art. 1).

${ }^{16}$ Zurriaráin, Roberto Germán, Los embriones humanos congelados. Un desafío para la bioética, Madrid: Ediciones internacionales universitarias, 2007, p. 192.

17 Zurriaráin, Roberto Germán, Los embriones humanos congelados..., 194.

18 Zurriaráin, Roberto Germán, Los embriones humanos congelados..., p. 186. 
Toda persona tiene los derechos y libertades proclamados en esta Declaración, sin distinción alguna de raza, color, sexo, idioma, religión, opinión política o de cualquier otra índole, origen nacional o social, posición económica, nacimiento o cualquier otra condición (art. 2)

Roberto Andorno destaca la gran importancia que tiene el reconocer la dignidad ontológica en el campo de la bioética, y de este modo menciona:

La preocupación central de la bioética es que las prácticas biomédicas estén en armonía con el respeto de la dignidad humana. Éste constituye el punto de referencia decisivo para entender la actividad biomédica en general y darle sentido último. En otras palabras, la idea de que cada individuo posee un valor intrínseco e inalienable opera como el necesario telón de fondo, no sólo de cada decisión clínica concreta, sino de la teoría bioética como un todo y de las normas que regulan la materia. ${ }^{19}$

Y más adelante:

La dignidad intrínseca, que se refiere al valor que posee todo ser humano en virtud de su mera condición humana, sin que ninguna cualidad adicional sea exigible. Se trata de un valor que está indisolublemente ligado al propio ser de la persona y por ello es el mismo para todos y no admite grados. En este sentido, todo ser humano, aún el peor de los criminales, es un ser digno y por tanto, no puede, bajo ninguna circunstancia, ser sometido a tratamientos degradantes o inhumanos, como la tortura y la esclavitud. ${ }^{20}$

También plantea Andorno:

Pero en todos los casos la idea de dignidad humana juega un rol paradigmático que revela el sentido último de la actividad biomédica. Tener esta idea en mente ayuda a los profesionales de la salud a no perder de vista que cada paciente no es ni un $<<$ caso $>>$, ni una $<<$ enfermedad $>>$, ni un $<<$ diagnóstico $\gg$, sino que es una persona dotada de un valor inefable y que debe por tanto ser tratada con el mayor respeto y cuidado. Cuando se tiene esta actitud, se le está diciendo tácitamente al paciente: $<<$ usted es una persona y no un objeto $\gg ;$; $<<$ su existencia tiene un valor intrínseco, no sólo para usted, sino también para mí y para todos $\gg$. Estas afirmaciones, que normalmente están implícitas en la actividad clínica, no son en absoluto secundarias, sino que tienen una importancia fundamental para evitar la deshumanización de la labor médica. ${ }^{21}$

${ }_{19}$ Andonno, Roberto, Bioética y dignidad de la persona, pp. 35-36.

${ }^{20}$ Andorno, Roberto, Bioética y dignidad de la persona, p. 73.

${ }^{21}$ Andorno, Roberto, Bioética y dignidad de la persona, p. 38. 
La dignidad moral es aquella que le sobreviene a la persona en razón de su actuar moral, es decir, aquella que se adquiere, conserva o pierde, según la bondad y/o maldad moral de sus actos libres. En este aspecto, un criminal o una persona entregada a los vicios tendrían poca dignidad moral en comparación a una persona virtuosa con gran dignidad moral. La dignidad moral es tan variable como variables son los actos libres del ser humano tanto para lo bueno como para lo malo. Es importante precisar que la dignidad ontológica no cambia en razón de la dignidad moral de una persona, porque el obrar se fundamenta en la subsistencia personal y no viceversa, y así, tanto una persona entregada a los vicios como una persona virtuosa, ambas, conservan intacta su dignidad ontológica y por consiguiente los derechos humanos que se fundamenta en dicha dignidad; pero con relación a su dignidad moral existe una gran diferencia, pues en el caso del vicioso, su dignidad moral se ha reducido bastante; y en el caso de la persona virtuosa, su dignidad moral permanece íntegra tanto cuanto viva en la práctica de la virtud.

La dignidad moral, en cambio, hace referencia no al ser sino a su obrar. Esta dignidad no es poseída por todos de la misma manera, pues se trata de una dignidad dinámica, en el sentido de que es construida por cada uno a través del ejercicio de la libertad dirigida por nuestra razón. A diferencia de lo que ocurre con la dignidad ontológica -que es inalienable- la dignidad moral sí puede perder. La dignidad moral únicamente la pierde el propio ser humano si se comporta por debajo de lo que reclama su propia dignidad ontológica. ${ }^{22}$

La humanidad ha cometido el error, a lo largo de la historia, de negar la dignidad ontológica y los derechos humanos que se siguen de ella a delincuentes en razón de la degradación de su dignidad moral. Es importante señalar que un delincuente, aunque merece una pena por su delito, tal pena no debe atentar ni contra su dignidad ontológica ni contra sus derechos humanos, quedando así la pregunta: ¿hasta qué punto una determinada pena jurídica atenta o no en contra de la dignidad ontológica de una persona? Queda claro que los castigos físicos, como las mutilaciones, atentan gravemente a la integridad corporal de una persona, aunque ésta sea un delincuente.

La dignidad ética, hace referencia, no al ser de la persona, sino a su obrar. En tal sentido, el ser humano se hace él mismo mayormente digno cuando su conducta está dirigida a la realización del bien. Esta dignidad es el fruto de una vida virtuosa y, por tanto, admite diversos grados. Se trata de una dignidad dinámica, en el sentido de que es construida por cada uno a través del ejercicio de su libertad..$^{23}$

22 Zurriaráin, Roberto Germán, Los embriones humanos congelados..., p. 187.

${ }^{23}$ Andorno, Roberto, Bioética y dignidad de la persona, p. 73. 
La dignidad social es aquella que se determina según un rol social o de acuerdo a la fama o reputación que una persona tenga hacia dentro de una comunidad. En este aspecto, los antiguos títulos de nobleza buscaban resaltar este tipo de dignidad. La dignidad social siempre es dependiente y relativa a la comunidad. La discriminación socioeconómica asume, como supuesto, que la dignidad social está por arriba de la dignidad ontológica.

\section{A modo de conclusión}

Entender al ser humano como una persona singular que subsiste en la naturaleza racional puede ser una vía para una fundamentación filosófica de los derechos humanos, ya que la dignidad intrínseca del ser personal se estaría ubicando en un marco ontológico. De este modo, en el tema de la dignidad de la persona, la dignidad ontológica es lo primario, para posteriormente, desde ésta, fundamentar la dignidad moral y social. Sin embargo, en un ensayo de fundamentación teológica de los derechos humanos, la dignidad religiosa del ser personal, entendida como imagen y semejanza de Dios, sería el fundamento previo a la ontológica; y a su vez, esta última sería fundamento de la dignidad moral y social, respectivamente.

Plantear la relación ordenada entre la dignidad ontológica, moral y social de la persona y los derechos humanos, daría lugar a otro ensayo, pero se puede señalar aquí que si llega a existir un conflicto entre los derechos humanos, es porque en algún sentido se violenta en la misma praxis humana el orden que deben de guardar los tres aspectos de la dignidad descritos.

Por otra parte, en bioética, un principio en el que se ha hecho hincapié es el de la dignidad de la persona. En efecto, la intervención de la biotecnología en la biología humana no se limita a lo corpóreo biológico, sino que alcanza al ser personal porque la persona humana subsiste siempre con un cuerpo biológico. Siendo el cuerpo humano una realidad personal, la cuestión de la dignidad ontológica incluye necesariamente la realidad corporal.

La subsistencia de la persona humana con un cuerpo implica que desde su misma dignidad ontológica fluya el derecho a una integridad corporal, pues ésta es parte de la integridad personal, con la consecuencia ética de que lo corpóreo en la persona humana no debe ser tratado como un objeto de uso para experimentos biotecnológicos, sino como un as- 
pecto que forma parte de su ser persona que piensa, decide y siente; de ahí que en bioética se hable de la necesidad de respetar a lo biológico humano mediante el consentimiento válidamente informado, es decir, lo experimentable en la realidad biológica del cuerpo humano se limita por el derecho a la integridad corporal, en donde dicho derecho debe ser ejercido por cada persona, quien al subsistir en la naturaleza racional es conveniente que valore y decida con base en una información clara, veraz y completa. 